ATLRNATA

Paper ID \#7911

\title{
Flipping a Large-enrollment Fluid Mechanics Course - Is it Effective?
}

Dr. Carrie J. McClelland P.E., Colorado School of Mines 


\title{
Flipping a Large-enrollment Fluid Mechanics Course - Is it Effective?
}

\begin{abstract}
Introduction

Engineers of the future face increasing complexity in the problems that they will be addressing. Engineering problems and their solutions affect, and are affected by economic, social, and technical issues, at a global scale. In addition, technology and other aspects of society are changing rapidly. Therefore the skills and knowledge that students attain in college need to provide a foundation that will allow for them to be competent in a globalized, challenging, fluid profession. ${ }^{1}$ Therefore, not only will they need to be competent with current knowledge, they need to also learn how to learn so that they can continue to stay up to date as technology and other aspects of society continue to rapidly change. These challenges in combination with enrollment that continues to increase caused the author to re-structure how a large, lecture-based, sophomore level fluid mechanics course was being taught.

The philosophy of the re-structured course centers on this quote by Elliot Dunlap Smith, a past president of Carnegie Mellon University ${ }^{2}$ :

"Learning results from what the student does and thinks and only from what the student does and thinks. The teacher can advance learning only by influencing what the student does to learn."
\end{abstract}

Considering the above, the lecture format being used for the class was not providing what was needed for developing competent learners and engineers. In a lecture format, the professor does much of the doing and thinking for the students. The time spent lecturing can instead be used to structure opportunities for the students to do and think. In addition, by providing varied activities during class time, students can find ways that they best learn and can then possibly apply those methods to their future learning needs.

In order to free up in-class time, the course was converted to a flipped, or inverted, classroom. In a flipped classroom format, students watch lectures on the internet and take notes before class. This frees up in-class time to discuss concepts, complete hands-on activities, and work problems that traditionally were homework. With the flipped format, interaction and personalized contact between the students and teachers is increased. It also allows for students to take responsibility for their learning and to hopefully be more engaged. ${ }^{3}$

\section{Course Description}

The course involved is a sophomore-level course in fluid mechanics. It is one of two courses in the department that develop the concepts that are essential for students in the discipline to know 
before learning more complex material for their major. Understanding and application of fluidmechanics concepts is emphasized, along with investigation of how these concepts will relate to the students' future professions. The class meets twice a week for 75 minutes throughout a 16week semester, for a total of 32 meetings. Typically, there is a significant majority of male students, and around 30-45\% international students - most of whom are not native English speakers.

\section{Assessing the effectiveness of the flipped class format}

In order for the new course format to be considered effective, it needed to provide students with an experience that results in at least equivalent, if not improved, performance in the class. To determine effectiveness, the performance of students was compared between two different classes.

Two sections of mainly sophomores (69 and 80 students) were taught using a lecture format. Two other sections of students (65 and 81 students) were taught using a flipped format the next time the course was offered. Both courses used similar syllabi. The sections taught using a lecture format had assigned homework problems that were completed outside of class time. The sections that had the flipped format worked many of the same problems during class. The exams had similar problems that covered the same topics, and the final exams were identical. To determine the effectiveness of the flipped format, a comparison was made between the test scores for each section. In addition, the scores for each topic were compared. At the end of the semester, comments regarding the students' impressions of the flipped format were anonymously collected in conjunction with the course evaluations.

\section{Format of the Flipped Class}

For this particular course, the sequence of the topics presented remained the same from the previous lecture-based sections. Online videos were created for each topic that coupled graphics, PowerPoint slides, and the instructor's voice. Students were expected to read associated textbook sections, watch the video, and take notes before class. During class time, the instructor and two teaching assistants interacted with groups of students. Typically, time in class was spent briefly discussing the reading and videos, and working problems that had been assigned as homework problems for the lecture format sections. Occasionally, hands-on activities and demonstrations that had been part of the lecture format classes were also conducted. Three exams were given throughout the semester, along with a cumulative final exam.

\section{Comparison of Student Performance}

The average score for the final exam in the traditional lecture format was $83.67 \%$, and the average final exam score for the flipped format was $80.25 \%$. Figure 1 below charts a comparison of the total percentages as well as a comparison for selected topics. Note that the grades are not curved. 


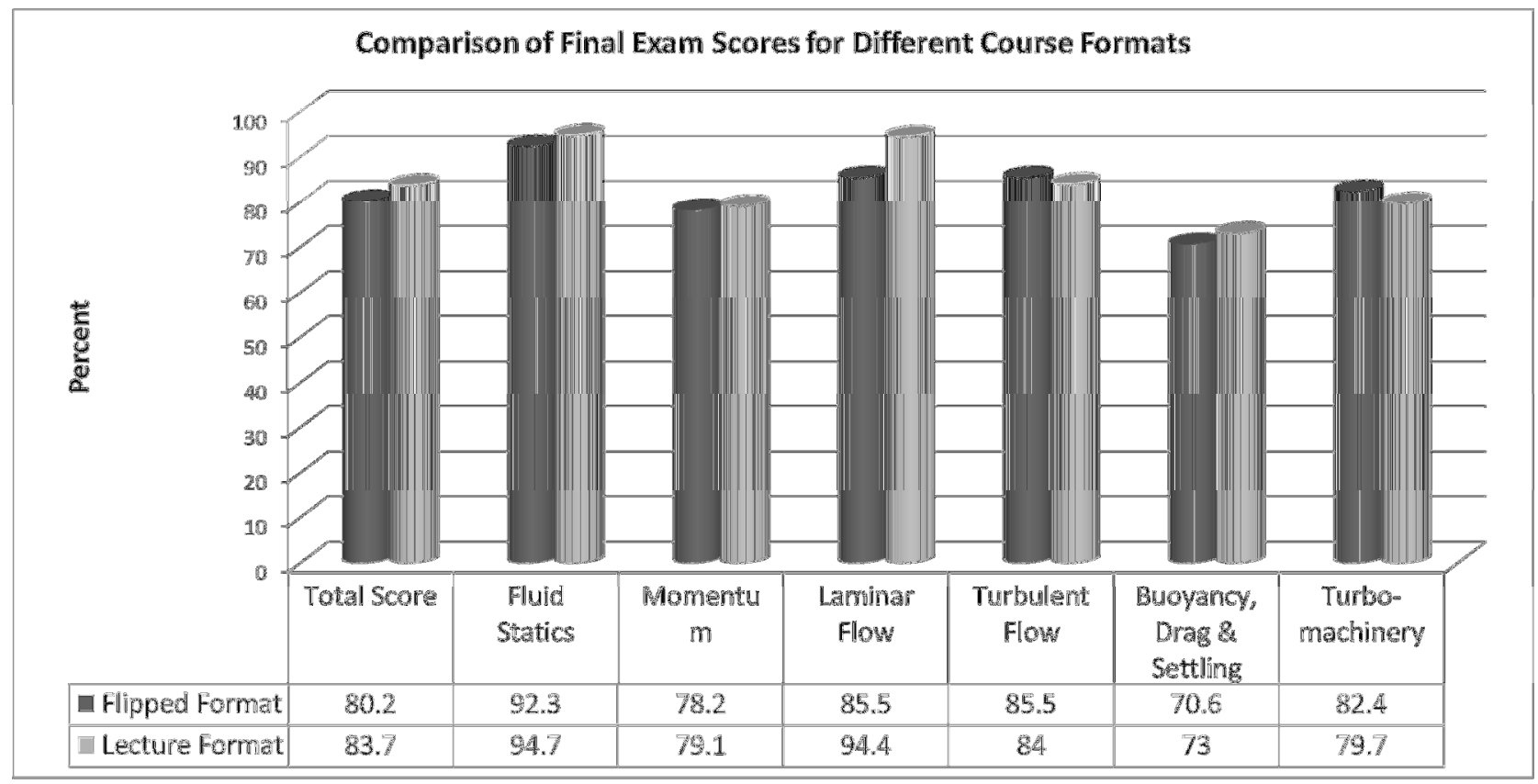

Figure 1 - The percentage scores for the final exam and selected topics are shown for each course format.

The scores for the lecture format exceed those of the flipped format for all but one topic. At first glance, this would then seem to support that the flipped format was not as effective for students' learning as the flipped format. However, the differences are so small that the differences may not be significant. Table 1 compares the averages, standard deviations, and the significance of each topic from the final exam. Notice that the difference between the average total scores was found to be significant. This indicates that the flipped format as implemented in this case was not as effective as a lecture-based class.

Table 1 - Comparison of Statistics for Final Exam Scores

\begin{tabular}{|l|l|l|l|l|}
\hline & \multicolumn{2}{l|}{ Average } & \multicolumn{2}{l|}{ Std. Deviation } \\
\hline & Flipped & Lecture & Flipped & Lecture \\
\hline Total* & 80.2 & 83.7 & 12 & 10.4 \\
\hline Fluid Statics* & 92.3 & 94.7 & 11.4 & 7.3 \\
\hline Momentum & 78.2 & 79.1 & 19.2 & 19 \\
\hline Laminar Flow* & 85.5 & 94.4 & 20.8 & 9.5 \\
\hline Turbulent Flow & 85.5 & 84 & 20.9 & 19.5 \\
\hline Buoyancy, Drag \& Settling & 70.6 & 73 & 24.7 & 25.8 \\
\hline Turbomachinery & 82.4 & 79.7 & 18 & 17 \\
\hline
\end{tabular}

$*$ t-test significant for $\mathrm{p}<0.05$ 


\section{Student Perceptions}

Students were asked to provide anonymous comments at the mid-term and at the end of the course regarding the flipped format and how well the course was helping them to learn. In general, there was overwhelming support for the flipped format.

Of over 100 anonymous course evaluations gathered at the end of the semester with comments regarding the flipped format, over $97 \%$ of the students expressed that they enjoyed the format and felt that they learned using it. There were only three students who expressed an interest in having more lecture time, and only one of the three asked for a return to an entirely lecture-based format. Some general comments include:

"I like having the class set up the way it is with the lectures in videos... and working problems in class. This way, I can re-watch things if I need to and it forces me to actually do the problems."

"The online lectures are a GREAT change of pace. Now you pause, rewind, and go at your own speed during a lecture, start working problems and bring your questions to class.”

Some students had thoughts on how the structure affected their learning. The last comment can be taken as negative or positive feedback, as one goal of the flipped format is to become a selfsufficient learner.

"I like the way the class is designed. You learn on your own."

"The reverse method is super effective for learning the material in a not stressful way."

"I learned more in this class than any class I have taken..."

"It really made effort count as far as you could learn as much as you wanted."

"The flipped structure of the class fosters a better learning environment and allows time for all students to matter what their schedule, to ask questions and/or get help."

"Not effective at all. Have not learned anything from prof, learned everything by myself!"

Regarding watching videos outside of class for the "lecture" portion of the course, many students felt that it was beneficial to be able to watch the videos at their own pace and re-watch them as necessary. Varying viewpoints are shown below:

"I like watching the lectures at home so I can take my time trying to learn."

"If the lecture is not watched, ...the class itself is not helpful as you don't know what's going on to ask questions." 
"Videos... are great tools to learn. You can watch the lectures over for better understanding and to study."

"Make the videos an extra part of the course and go back to more lecture."

"Online lecture allows us to get much more out of this class than lecture alone."

"Sometimes there are important notes that are essential to solving the problems that aren't well explained..."

Some comments regarding working problems during class:

"The time spent in class to go over problems is very helpful and helps full understanding of the problems because if issues arise we can ask for immediate help."

"Working problems in class is very helpful because I can work with classmates and get help right away."

"I feel that I learned more because we did homework in class where I could ask questions. It always makes class more exciting because we are doing something rather than just listening to a lecture."

\section{Assessment of Effectiveness}

The flipped format is effective for learning fluid mechanics concepts, and students strongly felt that the flipped format enabled them to learn successfully. However, in the format as presented in this paper, a flipped format class is less effective than a lecture-based class, as measured by test performance. Comparing the student performance for both methods shows that a flipped format can attain very similar student performance. This result is not very surprising, given that the same lecture notes, texts, and problems were used. The course did not contain any more or significantly different topics and tasks regardless of the course format.

However, comparisons of the perceptions that students have regarding the two course formats indicates that a flipped format is more effective in some aspects. Most students showed that they preferred this format to a traditional lecture. Whether they preferred it because they felt it made the course more enjoyable, or it worked well with how they learn, or it allowed them to learn at their own pace, they may perceive that they did better and learned more - even if the grades don't show much of a difference, or even a slight decrease. It is the author's opinion that an average of $80 \%$ on a final exam should still be considered a success. Therefore, a flipped class can be effective (albeit with a lower average than a lecture-based class), and may lead students to perceive that they are learning more effectively.

One key observation of the instructor that may help to explain the difference in performance is that the lower performing students did not work as diligently during class problem solving sessions, often were not prepared to discuss the online lectures when they came to class, and had 
low rates of attending supplemental problem solving sessions and office hours. Utilizing the viewing statistics provided by YouTube, it was found that the percentage of students who actually viewed the videos before class varied widely throughout the semester. See Figure 2. As can be seen on the figure, the students began the semester fairly motivated, with most students watching the lectures before coming to class. As the semester got busier, many students likely found it easy to skip watching the video since they were not going to be held accountable for the material until the exams. (YouTube statistics also show drastic spikes in views immediately prior to the exams.)

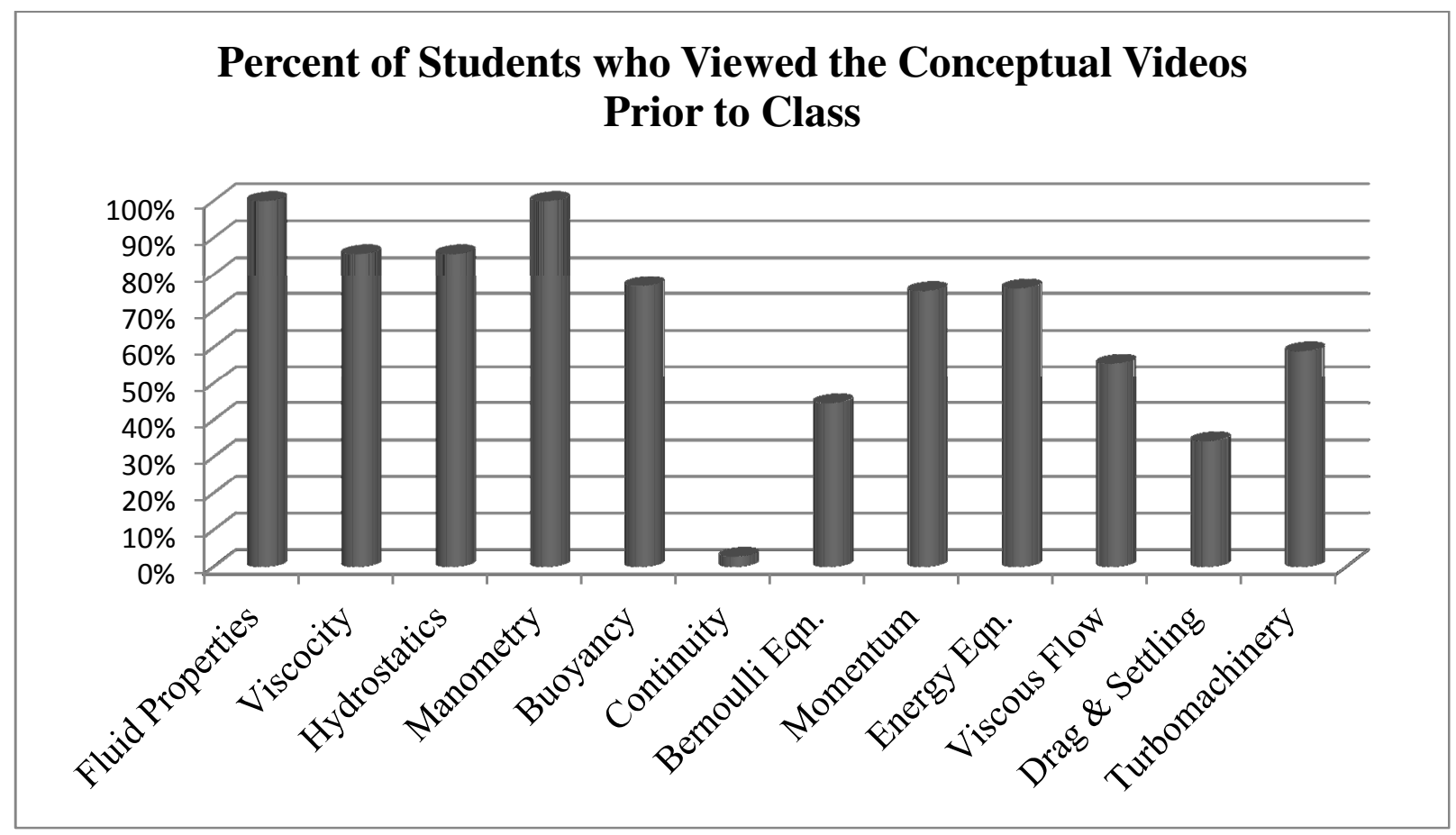

Figure 2 - The percentage of students who "did their homework" prior to class.

\section{Considerations for Future Improvement of the Flipped Format}

The flipped format used for this study could be much more effective by concentrating on two aspects, which are focusing on fostering self-motivation, and making better use of the time in class. Self-motivation plays a much larger role in student success with the flipped format. It is difficult for students to succeed under a flipped format if they lack the skills or motivation to study the material without a tangible benefit (i.e. a grade), prioritize and manage their time, and seek help from others when they need it. Investing a small bit of time in the early sessions of the course that focus on aspects such as problem-solving procedures and effective strategies for studying and time management, self-awareness of learning and learning styles, setting goals for the class, and teaching students how to use the technology used in the class can provide the foundation needed for students to succeed in a flipped, or more self-directed, format. ${ }^{4}$ Providing 
this instruction can also build the skills necessary for students to be life-long learners and to address ABET criteria $3^{5}$

Student motivation can also be encouraged by setting explicit expectations, providing challenges, arousing curiosity and offering some choices. ${ }^{2}$ The best way to accomplish this is to ensure that students are well informed, and the time during class is used very effectively. A detailed syllabus describing what is needed to be done to prepare for class, done in class, and done to follow up after class is essential for helping students to feel informed and more in control of their learning. Challenges can be provided and curiosity aroused by providing time in class for demonstrations, collaborative problems, and discussions of how concepts relate to their chosen careers. ${ }^{6}$ Another way to encourage student-motivation is to require some low stakes assignments, such as quizzes on the video concepts, at the beginning of class to ensure that the necessary preparations are made. ${ }^{7}$

\section{Future Directions for this Study}

Based upon the results of this study showing that flipping a class can be an effective way to learn and gauging high student satisfaction with the method, this format will be implemented in the next offering of the course. In addition, the suggestions listed above will be implemented to make better use of the in-class time and to help students "learn how to learn." A follow-up study will be conducted that will survey the concept retention of students who studied under both formats and also investigate the effectiveness of learning with this new iteration of the flipped format.

\section{Bibliography}

1. L. Dee Fink, Creating Significant Learning Experiences: An Integrated Approach to Designing College Courses, Jossey-Bass Imprint, John Wiley and Sons (2003)

2. Ambrose, S., Bridges, M.W., DiPietro, M., Lovett, M.C., Norman, M.K., (2010). How Learning Works: Seven Research-Based Principles for Smart Teaching. Jossey-Bass, pp. 1.

3. Bergmann, J., Overmyer, J., Wilie, B., (2012) The Flipped Class: Myths vs. Reality, The Daily Riff, April 14, 2012. Accessed online: http://www.thedailyriff.com/articles/theflipped-class-conversation-689.php

4. Weinstein, C.E., Meyer, D.K., Husman, J., McKeachie, W.J. \& Svinicki, M. (2011). "Teaching Students How to Become More Strategic and Self-Regulated Learners," in McKeachie's Teaching Tips: Strategies, Research and Theory for College and University $\underline{\text { Teachers, }}$ 13th edition, McKeachie, W.J. \& Svinicki, M. Houghton-Mifflin; Boston, MA. 
5. Hofer, B., (2011). "Motivation in the College Classroom," in McKeachie's Teaching Tips: Strategies, Research and Theory for College and University Teachers, 13th edition, McKeachie, W.J. \& Svinicki, M. Houghton-Mifflin; Boston, MA.

6. Toto, R. and Hien Nguyen, (2009). Flipping the Work Design in an Industrial Engineering Course. $39^{\text {th }}$ ASEE/IEEE Frontiers in Education Conference, San Antonio, TX.

7. Zappe, S., Leicht, R., Messner, J., Litzinger, T., and Lee, H.W. (2009). 'Flipping' the Classroom to Explore Active Learning in a Large Undergraduate Course. Proceedings, American Society for Engineering Education Annual Conference \& Exhibition, Austin, TX. 